\title{
Acute Viral Bronchiolitis: Physician Perspectives on Definition and Clinically Important Outcomes
}

\author{
Ricardo M. Fernandes, MD, PhD, ${ }^{1,2 \star}$ Maria Gabriela Andrade, ${ }^{2}$ Carolina Constant, MD, ${ }^{1,3}$ \\ Duarte Malveiro, MD, ${ }^{4}$ Manuel Magalhães, MD, ${ }^{5,6}$ Daisy Abreu, BSc, $\mathrm{MSc}{ }^{2}$ Inês Azevedo, MD, PhD, ${ }^{5,7}$ \\ Eduarda Sousa, $\mathrm{MD},{ }^{4}$ Rizério Salgado, $\mathrm{MD}^{8}{ }^{8}$ and Teresa Bandeira, $\mathrm{MD}, \mathrm{PhD}^{1,9}$
}

\begin{abstract}
Summary. Background: Two key limitations hamper intervention research in bronchiolitis: the absence of a clear definition of disease, and the heterogeneous choice of outcome measures in current clinical trials. We assessed how paediatricians and general practitioners (GPs) perceived definition and clinically important outcomes in bronchiolitis. Methods: A nationwide online survey (ABBA study) was conducted through the Portuguese Society of Paediatrics and GPs' mailing lists. We assessed agreement with statements on bronchiolitis definition, and participants were asked to score the relative importance of several outcomes. Principal component analysis (PCA) explored dimensions underlying disease definition. Outcomes were ranked by mean score and proportion given highest score. Results: We included 514 paediatricians and 165 GPs (overall 59\% were board-certified). Most paediatricians (76.5\%) agreed with a definition based on coryza, wheezing and/or crackles/rales, compared to $38.1 \%$ GPs $(P<0.001)$. Less than $5 \%$ physicians agreed with a definition commonly used in clinical trials ( $<12$ months, first episode of wheeze). We retained three dimensions on PCA: one based on coryza, rales/crepitations and no sudden onset; another on number of episodes and age; and a third on wheeze. Dimensions varied by physician specialization and training $(P<0.01)$. Hospital admission and respiratory distress were top rated outcomes by both groups of
\end{abstract}

\footnotetext{
${ }^{1}$ Department of Paediatrics, Hospital de Santa Maria, Centro Académico de Medicina de Lisboa, Lisboa, Portugal.

${ }^{2}$ Clinical Pharmacology Unit, Instituto de Medicina Molecular, Faculty of Medicine, University of Lisbon, Lisboa, Portugal.

${ }^{3}$ Department of Paediatrics, Unidade de Torres Vedras, Centro Hospitalar do Oeste, Torres Vedras, Portugal.

${ }^{4}$ Department of Paediatrics, Centro Hospitalar Lisboa Ocidental, Lisboa, Portugal.

${ }^{5}$ Department of Paediatrics, Faculty of Medicine, University of Porto, Porto, Portugal.
}

${ }^{6}$ CINTESIS—Center for Research in Health Technologies and Information Systems, Porto, Portugal.

${ }^{7}$ EPI Unit, Institute of Public Health, University of Porto, Porto, Portugal.

${ }^{8}$ Unidade de Saúde Familiar S. Julião, Centro de Saúde de Oeiras, Oeiras, Portugal.

${ }^{9}$ Clínica Universitária de Pediatria, Faculty of Medicine, University of Lisbon, Portugal

Conflict of interest: None.

Funding source: Pulmonology Society of the Portuguese Society of Paediatrics.

Results from this study were presented at the European Respiratory Society International Congress, Munich, 2014 (Eur Respir J 2014 44:Suppl 58, P1257).

${ }^{*}$ Correspondence to: R.M. Fernandes, MD, PhD, Department of Paediatrics, Hospital de Santa Maria, Centro Hospitalar Lisboa Norte and Clinical Pharmacology Unit, Instituto de Medicina Molecular, Universidade de Lisboa, Avenida Professor Egas Moniz, 1649-028 Lisboa, Portugal.

E-mail: rmfernandes@campus.ul.pt

Received 20 October 2014; Revised 9 August 2015; Accepted 22 August 2015.

DOI 10.1002/ppul.23346

Published online 23 November 2015 in Wiley Online Library

(wileyonlinelibrary.com).

(C) 2015 Wiley Periodicals, Inc. 


\begin{abstract}
physicians. Conclusions: Physician definitions of bronchiolitis have considerable variability and often mismatch those of clinical trials. Rating of important outcomes was consistent. Our results highlight the need for a robust standardized definition of acute bronchiolitis in infants and support the development of a core outcome set for future clinical trials. Pediatr Pulmonol. 2016;51:724-732. @ 2015 Wiley Periodicals, Inc.
\end{abstract}

Key words: bronchiolitis; wheezing; clinical trial; outcomes; phenotype.

\section{INTRODUCTION}

Acute viral bronchiolitis is the most common lower respiratory tract infection in infants. ${ }^{1}$ It entails substantial clinical and financial burden across different levels of care. Treatment is controversial, and there is wide practice variation and inconclusive evidence for many therapeutic approaches. ${ }^{2,3}$ Systematic reviews in this field have highlighted two shortcomings in clinical trial design: the absence of a clear definition of disease, and the heterogeneous choice of outcome measures. ${ }^{4,5}$

While bronchiolitis is a relatively straightforward clinical diagnosis for most child health practitioners, no standardized set of diagnostic criteria exists. ${ }^{1,6-10} \mathrm{~A}$ Delphi panel from a local guideline in the United Kingdom reported consensus on bronchiolitis as 'a seasonal viral illness characterised by fever, nasal discharge and dry, wheezy cough', with "fine inspiratory crackles and/or high pitched expiratory wheeze".11 However, definitions may vary by auscultatory findings, age, number of episodes or other parameters. ${ }^{9,12,13}$ Furthermore, the label "bronchiolitis" may overlap with acute wheezing and asthma, which hampers the interpretation of current evidence. ${ }^{14,15}$ Empirical data is lacking on physician's perspectives of definitions and their determinants.

The second issue relates to the inconsistency in reported outcome domains measured in bronchiolitis trials. ${ }^{4,16}$ This limits the interpretability of trial findings and the opportunity for pooling results in meta-analysis. Initiatives such as OMERACT and COMET have supported the development and use of agreed standardized collection of outcomes, that is, core outcome sets, to be used, as a minimum, in all trials for a specific clinical area. ${ }^{17,18}$ Core outcome sets should be meaningful for key stakeholders. However, there is scarce evidence on which outcomes in bronchiolitis are clinically relevant.

The ABBA survey aimed to assess the perspectives of physicians, across the nation, on definition of bronchiolitis, and on clinical importance of different outcomes in this field. We engaged and compared perspectives from paediatricians and general practitioners (GPs), as both groups are key stakeholders involved in the management of bronchiolitis of varied severity at different levels of care, and have distinct background and training that may influence these perspectives.

\section{MATERIALS AND METHODS}

\section{Study Design and Subjects}

The ABBA study was a cross-sectional electronic survey targeting paediatricians and GPs working in Portugal, both board-certified physician specialists and postgraduate physicians in a residency training program. Paediatricians were current members of the Portuguese Society of Paediatrics (SPP), which has an open membership across levels of care. Electronic contact information was provided by the organization, after review and approval of the research protocol. Subjects with invalid e-mail addresses were excluded. We reached GPs who were registered in any of three national GP mailing lists with the support of the Portuguese Association of General Practitioners (APMGF).

\section{Questionnaire}

A multidisciplinary panel from the Pulmonology section of the SPP and the APMGF designed a questionnaire in Portuguese on various topics of bronchiolitis; definition and outcomes are the focus of this paper. The instrument was developed using a structured approach. Based on a literature review and the panel's expertise, items were formulated for each construct and examined for face validity. Item selection and reduction was achieved through consensus. We obtained 18 items on definitions and outcomes, and we collected data on physicians' training and workplace (Appendix). Response formats included multiple choice items, ordinal ratings (1-5) and 5-point Likert items (ranging from disagree completely to agree completely).

First, we asked practitioners to express their level of agreement with six statements on key history and clinical findings in defining bronchiolitis. These included onset of symptoms, preceding coryza, auscultatory findings (crackles/rales and wheezing), upper age limit and maximum number of episodes. Regarding outcomes, participants were asked to score the importance given to a predefined list of 12 outcomes in the interpretation and applicability of clinical trial results. We included outcomes that have been previously reported in bronchiolitis trials (e.g., hospital admission, clinical severity), and added outcomes recognised as relevant but often missing in this field (e.g., quality of life, parent-reported symptoms). The 
survey was developed using the SurveyMonkey platform (www.surveymonkey.com), and the instrument was pilot tested for acceptability and feasibility.

\section{Implementation}

The survey ran from 5th April to 22nd May, 2013. A modified Dillman technique was employed to optimize the response rate, including up to four reminder e-mails and a small incentive. Paediatricians were contacted through personalized e-mail invitations, with a unique link that prevented multiple entries. An e-mail invitation with an open link was sent to each GP mailing list. Consent was implied by survey completion, and data was anonymized for analysis. The Ethics Committee of Centro Hospitalar Lisboa Norte/Faculdade de Medicina de Lisboa approved this study.

Preliminary data indicated approximately 1,300 members of SPP from a universe of around 1,750 paediatricians and 400 residents registered nationwide in 2011. About 1,400 GPs were registered in all three mailing lists. Previous electronic surveys performed within smaller paediatric organizations reached response rates up to 60-75\%. We anticipated 40-50\% responses from paediatricians, but a lower rate from GPs due to the method of recruitment.

\section{Statistical Analysis}

\section{Definitions of Bronchiolitis}

We stratified results by paediatricians and GPs, and compared responses to Likert items using the MannWhitney test. We evaluated whether physician perspectives were in agreement with two existing definitions, one based on a consensus approach for a local guideline, ${ }^{11}$ the other based on inclusion criteria used in recent randomized trials (operational criteria shown in Table S1), using the $\chi^{2}$ test. ${ }^{19,20}$

We used exploratory factor analysis to examine whether any meaningful dimensions could be distinguished underlying the perspectives on definitions of bronchiolitis. ${ }^{21}$ Principal component analysis (PCA) is based on item correlations; items that correlate highly with each other are clustered in one factor/component, and share variance explained by the underlying dimension. PCA aims to explain as much total variance with a minimal number of components. We performed PCA including data from all participants on the six items on definition of bronchiolitis. We determined the number of components to retain based on two criteria: magnitude of the eigenvalue $>1$ (main criteria) and examination of scree plot. Selected components were rotated to facilitate interpretation and to generate component loading scores, which measure the association between items and the underlying component. We used the varimax orthogonal rotation, since components did not show considerable correlation between each other $(<0.2)$. Sampling adequacy was assessed through the Kaiser-Meyer-Olkin measure, and we used the Bartlett's test of sphericity to test for homogeneity. Items with conventional loading $>0.4$ (absolute value) were interpreted for each component. Using the resulting components as dependent variables, we used multivariate analysis of variance (MANOVA) to examine associations with group of physician (paediatricians vs. GPs), training (resident vs. specialist) and location (Lisbon and south vs. other regions).

\section{Outcomes in Bronchiolitis}

We analyzed the distribution of scores given to each outcome by paediatricians and GPs, and identified outcomes that were rated 4 or 5 by over $80 \%$ of participants. Further, we ranked outcomes within each subject (for equal scores, standard competition ranking, that is, "1224" was used). We then calculated for each outcome the proportion of participants giving it the highest score/ranking. Overall ranking of outcomes was based on this proportion, as well as on the highest mean scores.

For all analyses, participants with incomplete responses were excluded for the corresponding parameter, with no imputation of missing data. $P$ values $<0.05$ were considered statistically significant. All analyses were performed using SPSS for Mac and Windows (SPSS Inc, version 21.0).

\section{RESULTS}

A flow diagram of participant recruitment is shown in Figure 1. We sent 1,218 invitations to potentially eligible SPP members, and included 514 (response rate $44 \%$ ). Of approximately $1,400 \mathrm{GPs}$ registered in mailing lists, 165 subjects participated (estimated $12 \%$ response rate). Complete responses were available from more than $90 \%$ paediatricians and more than $70 \%$ GPs. Table 1 summarizes the demographic characteristics of included participants. For both paediatricians and GPs the majority of responders were specialists $(59.2 \%)$ and worked in Lisbon or north of Portugal (74.9\%). Of paediatricians, $42.3 \%$ worked in all practice settings (ambulatory, that is, outpatient, emergency department and hospital), while most GPs provided paediatric ambulatory care $(94.5 \%)$, and $29.7 \%$ also worked in paediatric emergency settings.

\section{Definitions of Bronchiolitis: Descriptive Statistics}

The perspectives of paediatricians $(n=494)$ and GPs $(n=147)$ on key history and clinical findings are shown in Figure 2 (number of episodes and age), and Figure 3 and Table S2 (symptoms and signs). Most physicians on both groups agreed or agreed completely with presence of 


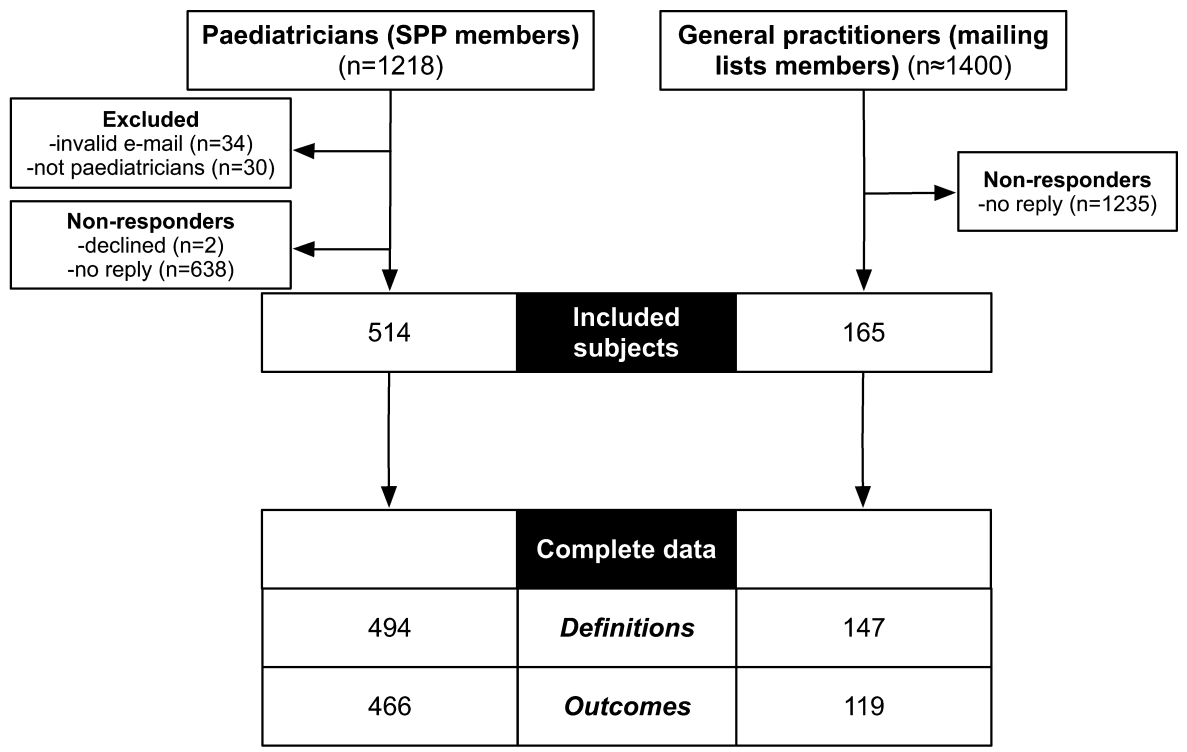

Fig. 1. Study flowchart of paediatricians and general practitioners.

wheezing on auscultation $(92.9 \%$ paediatricians and 95.2\% GPs $)(P=0.06)$. However, we found significant differences between groups on all other parameters $(P<0.001$ for all comparisons). Most paediatricians agreed or agreed completely with preceding coryza and presence of crackles/rales $(92.5 \%$ and $89.5 \%$, respectively), and disagreed or disagreed completely with sudden onset of symptoms (68\%). Further, they most often restricted the diagnosis of bronchiolitis based on number of episodes (up to three episodes $47.3 \%$, only first episode $32.4 \%$ ), and upper age limit (up to 24 months $76.2 \%$, up to 12 months $13.8 \%$ ). On the contrary, $52.4 \%$
GPs agreed or agreed completely with sudden onset of symptoms, with a lower proportion than paediatricians agreeing or agreeing completely with preceding coryza and presence of crackles/rales $(70.1 \%$ and $42.9 \%$, respectively). Also, many GPs did not restrict bronchiolitis by number of episodes $(56.3 \%)$ or age $(16.7 \%)$.

A definition of bronchiolitis close to the Nottingham guideline had the agreement of $76.5 \%$ paediatricians and $38.1 \%$ GPs $(P<0.001)$. A commonly used clinical trial definition of bronchiolitis (limited to a first episode of wheezing below 12 months) had the agreement of only $4.1 \%$ paediatricians and $2.8 \%$ GPs $(P<0.001)$.

TABLE 1-Demographic Characteristics of Paediatricians and General Practitioners

\begin{tabular}{|c|c|c|}
\hline Demographic characteristics & Paediatricians $(\mathrm{n}=514)^{1}$ & General practitioners $(n=165)^{1}$ \\
\hline \multicolumn{3}{|l|}{ Level of training-n $(\%)$} \\
\hline Resident & $215(42)$ & $62(38)$ \\
\hline Specialist & $299(58)$ & $103(62)$ \\
\hline \multicolumn{3}{|c|}{ Time since graduation-median [P25-75] years } \\
\hline Resident & $5(4-6)$ & $4(3-5)$ \\
\hline Specialist & $14(10-25)$ & $9.5(7-24.5)$ \\
\hline \multicolumn{3}{|l|}{ Practice setting-n $(\%)^{2}$} \\
\hline Ambulatory care & $319(63)$ & $156(95)$ \\
\hline Emergency department & $432(86)$ & $49(30)$ \\
\hline Hospital care & $362(72)$ & $1(1)$ \\
\hline \multicolumn{3}{|l|}{ Workplace- $\mathrm{n}(\%)^{3}$} \\
\hline Lisbon region & $206(41)$ & $65(41)$ \\
\hline North & $175(35)$ & $50(32)$ \\
\hline Center & $80(16)$ & $34(21)$ \\
\hline Other & $42(8)$ & $10(6)$ \\
\hline
\end{tabular}

\footnotetext{
${ }^{1}$ Results were calculated based on the number of respondents to a particular question; data available from $n=514$ paediatricians and $n=165$ general practitioners unless specified.

${ }^{2}$ Data available from $\mathrm{n}=503$ paediatricians; practice settings were not mutually exclusive.

${ }^{3}$ Data available from $n=503$ paediatricians and $n=159$ general practitioners.
} 


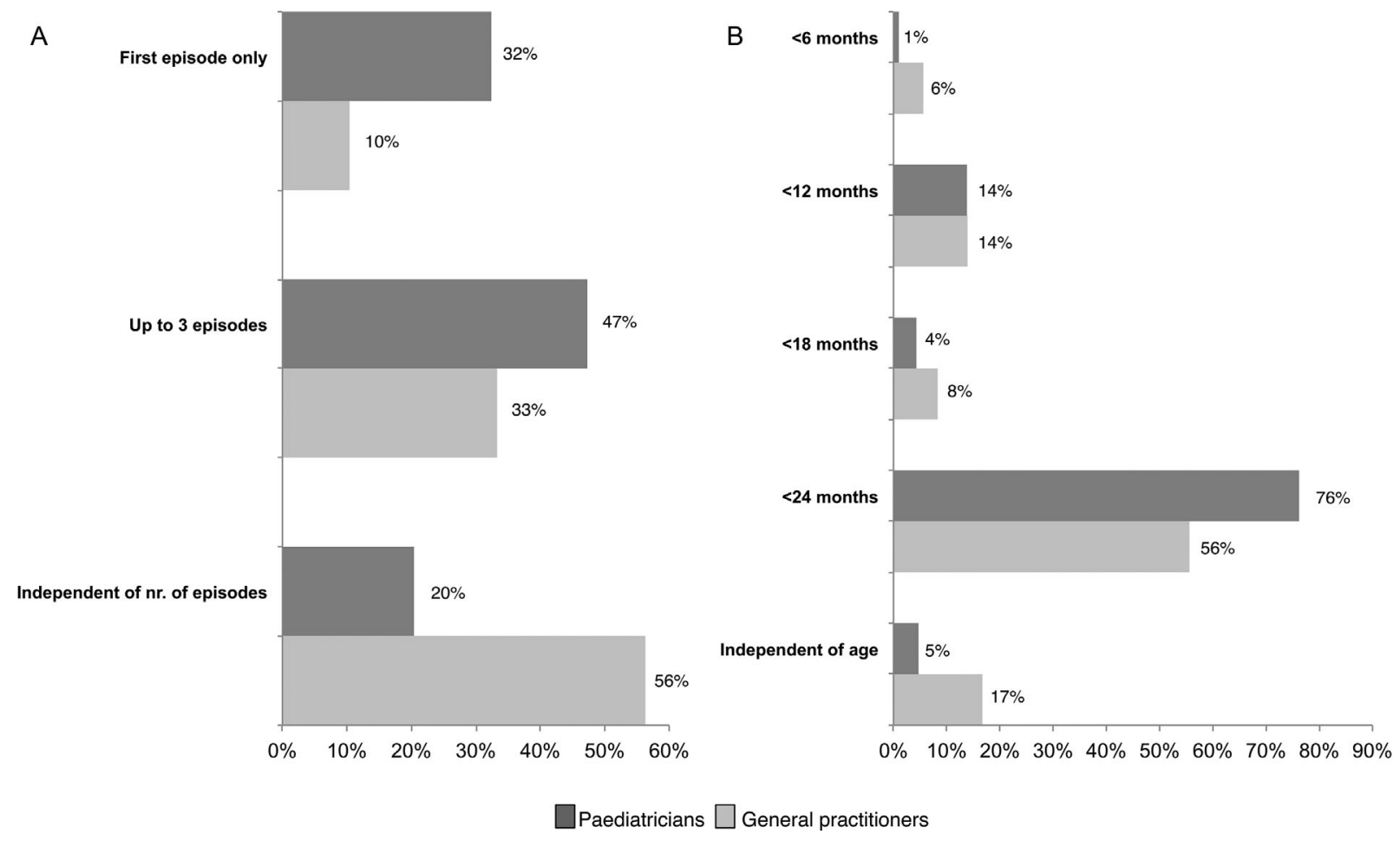

Fig. 2. Perspectives of paediatricians and general practitioners on number of episodes (panel A) and age (panel B) limits for the definition of bronchiolitis.

\section{Definitions of Bronchiolitis: Factor Analysis}

Principal component analysis was conducted with data from 644 participants: the correlation matrix between the six items is shown on Table S3, each component's eigenvalues and percentages of variance explained are shown on Table S4, and a scree plot on Figure S1. Three components that explained $63.9 \%$ of the variability were retained. The rotated component matrix is shown in Table 2. The first component correlated with "coryza preceding symptoms" and "crackles/rales on auscultation," but was inversely correlated with "sudden onset of symptoms" (Principal Component 1-PC1, defined as "coryza and crackles/rales, no sudden onset"). The second component was determined by "number of episodes" and "age of the child" (PC2, "age and episodes"), which varied together, with a stronger correlation with the latter. The third component was mostly correlated with "wheeze on auscultation" (PC3, "wheeze").

Using MANOVA, we found significant associations of underlying components with physician group $(P<0.001)$ and level of training $(P=0.003)$, but not geographical workplace $(P=0.811)$. In particular, paediatricians and residents assigned higher scores on PC1 (i.e., they placed more emphasis on this component), as compared to GPs and specialists, respectively $(P<0.001)$. Compared to GPs, paediatricians scored lower on PC2 $(P=0.011)$ and PC3 $(P=0.002)$ (i.e., they placed less emphasis on these components).

\section{Outcomes in Bronchiolitis}

Table 3 presents results on the relevance given by physicians to different outcomes. Mean scores for all outcomes were close to or above four in both groups, and all medians were 4 (interquartile range 3-5). Most outcomes were rated 4 or 5 by over $80 \%$ of participants in both groups. Ranking outcomes by highest overall mean score and by more frequent highest score led to comparable results on the top outcomes, which were hospital admission and respiratory distress for both paediatricians and GPs. Outcomes which less than $80 \%$ paediatricians scored 4 or 5 included feeding tolerance, treatment harms, return visits, quality of life and sleep; the latter three had the lowest mean scores of all outcomes. Scores for need for oxygen therapy, recurrent wheezing and asthma were more frequently less than 4 or 5 by GPs when compared to paediatricians, both being among the lowest mean scores in the GP group.

\section{DISCUSSION}

To our knowledge, this study provides the first comprehensive assessment of bronchiolitis definitions from physicians. The debate over the definition of disease has lasted for decades, as the same diagnostic label is applied to children with important differences in their demographic, history and physical examination 


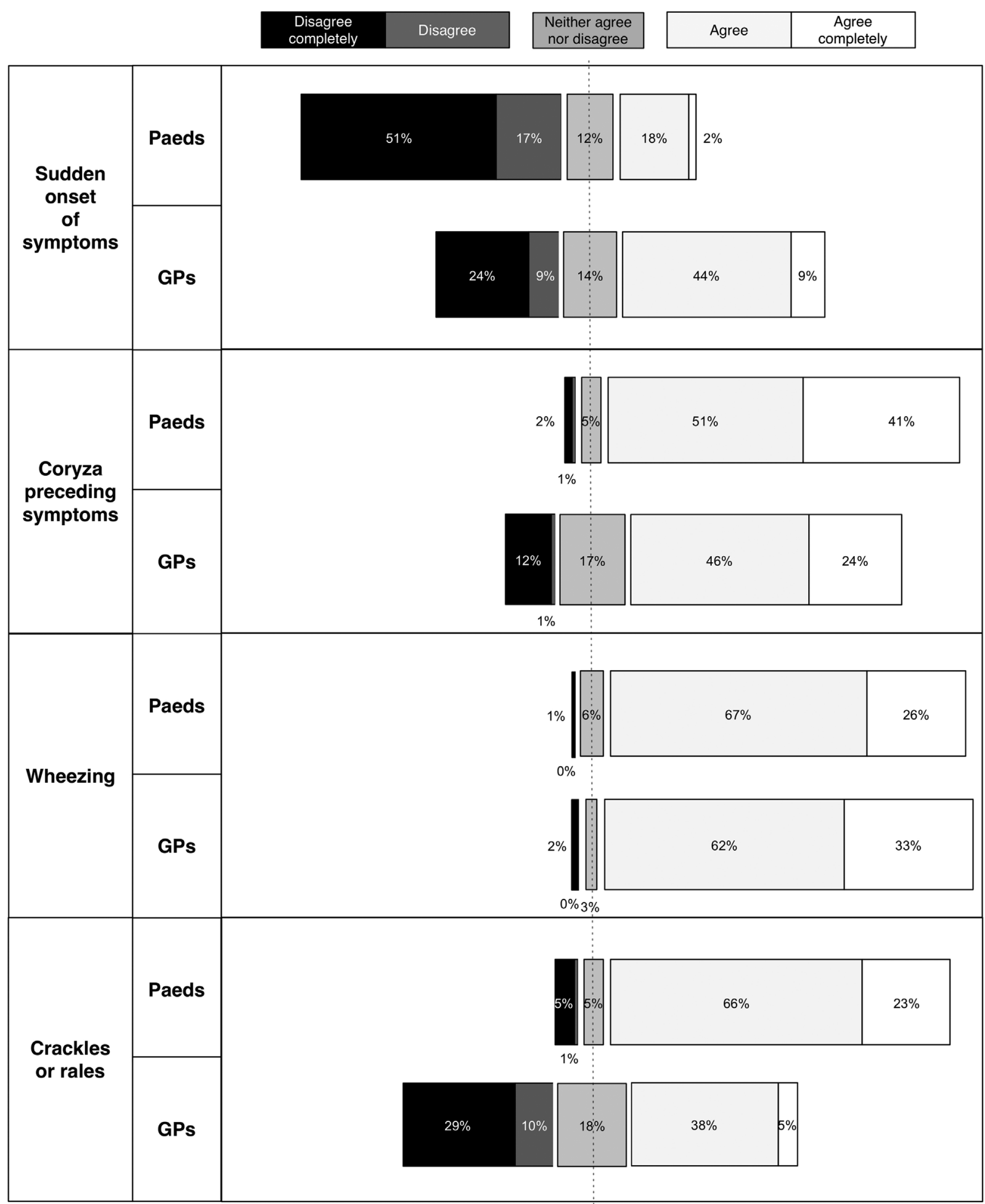

Fig. 3. Perspectives of paediatricians and general practitioners on key history and clinical findings in bronchiolitis.

features. ${ }^{6-13}$ Distinct perspectives have often been attributed to a geographical divide between the North American definition favouring a first episode of wheeze in up to 1- or 2-year olds, and the use of the term in the
United Kingdom and Australia, with crackles/crepitations in younger infants as hallmarks, with or without wheeze. $^{8,9}$ However, empirical evidence in this field is scarce. Our results suggest paediatricians have a broader 
TABLE 2-Perspectives on Definition of Bronchiolitis: Principal Component Analysis With Factor Loadings, Eigenvalues, and Explained Variances ${ }^{1,2}$

\begin{tabular}{lccc}
\hline & \multicolumn{3}{c}{ Principal components } \\
\cline { 2 - 4 } & PC1 & PC2 & PC3 \\
\hline Item & & & \\
$\quad$ Sudden onset of symptoms & $\mathbf{0 . 6 4 3}$ & 0.125 & 0.327 \\
Coryza preceding symptoms & $\mathbf{0 . 7 4 3}$ & -0.112 & 0.298 \\
Wheezing on auscultation & 0.021 & -0.027 & $\mathbf{0 . 9 3 8}$ \\
Crackles/rales on auscultation & $\mathbf{0 . 6 8 5}$ & 0.099 & -0.010 \\
Number of episodes & -0.365 & $\mathbf{0 . 5 9 9}$ & 0.122 \\
Age of the child & 0.188 & $\mathbf{0 . 8 5 5}$ & -0.118 \\
Eigenvalue before rotation & 1,65 & 1,151 & 1,035 \\
Explained variance $(\%)$ & 26.723 & 18.798 & 18.408 \\
Eigenvalue after rotation & 1.603 & 1.128 & 1.104 \\
\hline
\end{tabular}

${ }^{1}$ Factor loadings of absolute value $\geq 0.40$ are shown in bold.

${ }^{2}$ Rotation method: varimax with kaiser normalization.

view on auscultatory findings, including both wheezing and crackles/rales. This is in line with the Nottingham consensus, as well as with definitions mentioned in current practice guidelines. ${ }^{22,23} \mathrm{We}$ did find considerable disagreement between paediatricians on age for acute bronchiolitis and number of episodes, and none of the guidance documents adheres to strict limits on these parameters. Further, results from GPs clearly show a different perspective for most items, with only wheezing as a common feature. Thus we confirmed that physicians, at both individual and specialty-level, define bronchiolitis differently and we have identified heterogeneous clinical items that must be addressed in any future standardized definition of bronchiolitis.

The heterogeneity in disease definition has a considerable impact both for clinical practice and research in viral acute bronchiolitis. Variability between centers in diagnostic labelling of lower respiratory tract infections in young children has been shown to influence treatment practices, given the overlap with asthma and viralinduced wheeze. ${ }^{24}$ We found a striking gap between physicians' perspectives and the definition used in recent large clinical trials, mostly due to its 12 -month limit and restriction to a first episode. This has important implications for the external validity and implementation of trial findings. A majority of clinicians uses a broader definition of bronchiolitis that includes older children with recurrent episodes, and may find it hard to extrapolate results from these trials. On the other hand, they may not necessarily consider evidence from trials in children with recurrent pre-school wheezing as applicable to bronchiolitis. Conversely, there are arguments in favour

TABLE 3-Perspectives of Paediatricians and General Practitioners on Relevance of Outcomes in Bronchiolitis

\begin{tabular}{|c|c|c|c|c|c|c|c|c|}
\hline \multirow[b]{2}{*}{ Outcome } & \multicolumn{4}{|c|}{ Paediatricians $(n=466)$} & \multicolumn{4}{|c|}{ General Practitioners $(n=119)$} \\
\hline & $\begin{array}{c}\text { Mean } \\
\text { score }(\mathrm{SD})\end{array}$ & $\begin{array}{l}\text { Scored } \\
4 / 5 \text { by } \\
>80 \%\end{array}$ & $\begin{array}{c}\% \text { given } \\
\text { outcome as } \\
\text { highest score }\end{array}$ & $\begin{array}{c}\text { Rank (by mean } \\
\text { score/by } \% \\
\text { highest score) }\end{array}$ & $\begin{array}{c}\text { Mean } \\
\text { score }(\mathrm{SD})\end{array}$ & $\begin{array}{l}\text { Scored } \\
4 / 5 \text { by } \\
>80 \%\end{array}$ & $\begin{array}{c}\% \text { scoring } \\
\text { outcome as } \\
\text { highest score }\end{array}$ & $\begin{array}{c}\text { Rank (by mean } \\
\text { score/by } \% \\
\text { highest score) }\end{array}$ \\
\hline $\begin{array}{l}\text { Hospital } \\
\text { admission }\end{array}$ & $4.38(0.7)$ & Yes & 70 & $1 / 1$ & $4.42(0.8)$ & Yes & 74.8 & $2 / 2$ \\
\hline $\begin{array}{l}\text { Length of } \\
\text { hospital stay }\end{array}$ & $4.29(0.68)$ & Yes & 60.9 & $4 / 4$ & $4.21(0.85)$ & Yes & 59.7 & $5 / 5$ \\
\hline Return visits & $3.99(0.82)$ & No & 44.2 & $10 / 9$ & $4.11(0.94)$ & Yes & 53.8 & $9 / 10$ \\
\hline $\begin{array}{l}\text { Respiratory } \\
\text { distress }\end{array}$ & $4.37(0.64)$ & Yes & 67.8 & $2 / 2$ & $4.5(0.77)$ & Yes & 81.5 & $1 / 1$ \\
\hline $\begin{array}{l}\text { Need for } \\
\text { oxygen } \\
\text { therapy }\end{array}$ & $4.36(0.62)$ & Yes & 66.3 & $3 / 3$ & $3.99(0.97)$ & No & 50.4 & $12 / 11$ \\
\hline $\begin{array}{l}\text { Feeding } \\
\text { tolerance }\end{array}$ & $4(0.7)$ & No & 40.8 & $9 / 11$ & $4(0.87)$ & Yes & 47.1 & $11 / 12$ \\
\hline $\begin{array}{l}\text { Duration of } \\
\text { illness }\end{array}$ & $4.11(0.74)$ & Yes & 50 & $6 / 8$ & $4.2(0.84)$ & Yes & 58.8 & $6 / 8$ \\
\hline Sleep $^{1}$ & $3.83(0.83)$ & No & 35.6 & $12 / 12$ & $4.18(0.93)$ & Yes & 60.5 & $8 / 4$ \\
\hline $\begin{array}{c}\text { Treatment } \\
\text { harms }\end{array}$ & $4.11(0.79)$ & No & 51.5 & $7 / 7$ & $4.19(0.93)$ & Yes & 59.7 & $7 / 5$ \\
\hline Quality of life ${ }^{1}$ & $3.96(0.81)$ & No & 43.1 & $11 / 10$ & $4.22(0.89)$ & Yes & 59.7 & $4 / 5$ \\
\hline $\begin{array}{l}\text { Pulmonary } \\
\text { function }^{2}\end{array}$ & $4.2(0.78)$ & Yes & 59.2 & $5 / 5$ & $4.33(0.94)$ & Yes & 73.1 & $3 / 3$ \\
\hline $\begin{array}{l}\text { Recurrent } \\
\text { wheezing } \\
\text { and asthma }\end{array}$ & $4.1(0.93)$ & Yes & 55.8 & $8 / 6$ & $4.11(0.97)$ & No & 58.8 & $10 / 8$ \\
\hline
\end{tabular}

${ }^{1}$ Parent-reported measures.

${ }^{2}$ Refers to long-term lung function prognosis. 
of a strict definition. ${ }^{25,26}$ Jartti et al. showed both age and episodes are associated with factors such as viral aetiology and atopic characteristics, which may influence short- and long-term outcomes. ${ }^{13}$ In clinical trials, randomisation can balance these or other confounders that may affect treatment responses. However, both future trials and epidemiological, prognostic and even translational research in this field would benefit from a more robust case definition, with clear boundaries with other wheezing disorders. Since a balance is needed between study design and clinical practice, clarifying standardized definitions in current practice guidelines would help. Further, even if the clinical definition is kept broader, researchers could agree on major subgroups for stratification, based on current and upcoming markers for domains such as host susceptibility, agent virulence, immunopathogenesis, and environmental predictors.

Our exploratory factor analysis added to these findings by identifying three key dimensions of correlated clinical features that underlie individual perspectives, what we may call "physician-based phenotypes" of bronchiolitis. The weight given to each component varied by physician specialty and training, but not by practice or geographical location, hinting at differences due to clinical teaching and experience, or severity of disease seen across settings. These "physician-based phenotypes" should be put against patient data to clarify whether valid clinical phenotypes of bronchiolitis exist. Interestingly, two dimensions match previously proposed clinical phenotypes based on auscultatory findings: one characterised by crackles (close to the "coryza and crackes/rales, no sudden onset" component), the other by wheeze alone. ${ }^{9}$ The acoustic characteristics and pathological correlates of adventitious sounds might be markers of distinct host responses in bronchiolitis, and results from one small study suggest they lead to different long-term respiratory outcomes. ${ }^{27}$ Further, Sanchez et al found response to bronchodilator in infants with bronchiolitis could be predicted from wheeze characteristics. ${ }^{28}$ However, validating such phenotypes requires more evidence on their association with disease severity, prognosis and possibly treatment response. Furthermore, while a separate "age and episodes" component signals that physicians perceive these parameters independently, we've shown these and other putative phenotype-defining traits interact and must be approached coherently for an inclusive definition. ${ }^{29}$

Our study also addressed the critical issue of outcome selection, which has been often overlooked in bronchiolitis intervention research. Previous systematic reviews of trials have repeatedly found variability in measured outcome domains and instruments used, noting the absence of guidance on clinically important outcomes. ${ }^{4,5}$ Developing a core outcome set that is relevant to all stakeholders would be a major step forward in acute viral bronchiolitis research. We have made a first contribution by evaluating the physician perspective, and found hospital admission and respiratory distress as the highest ranked and rated outcomes. Interestingly, there was remarkable consistency between paediatricians and GPs for these top outcomes, but some differences were found in outcomes that scored below a commonly used threshold for consensus (i.e., 80\%). Outcomes such as quality of life or sleep were more valued by GPs, which highlights the need to incorporate stakeholder perspectives across levels of care given the wide spectrum of severity of bronchiolitis. Overall, all listed outcomes were highly rated by either clinician group, and should be considered in a future core outcome set. Importantly, this study is just a preliminary step in a structured core outcome set development process. ${ }^{18,30}$ Our results may be used to support a formal consensus approach involving key stakeholders (other clinicians, researchers, parents, regulators), across settings and internationally. Both bronchiolitis definition and outcome selection could be addressed in such an initiative.

Strengths and limitations of our study must be considered. First, we focused on a limited predefined set of clinical findings and outcomes, both of which may not encompass all relevant items. Our purpose was to generate representative data, and further in-depth analysis will require qualitative research techniques. Second, the demographics of participating paediatricians suggest they are likely representative nationwide and across settings, oversampled for residents. The sample of GPs was smaller and many worked in paediatric emergency; while primary care paediatrics is mainly provided by GPs, there could be a possible bias of our sample towards views closer to those of paediatricians. It should be noted that the open link method of invitation for GPs carries a risk of multiple responses by a same participant, although survey settings were restricted to one response per computer. Moreover, answers in this survey may not accurately reflect individual practice when diagnosing bronchiolitis. Although we used standardized nomenclature of adventitious sounds, terminology varies and reliability of stethoscope examination is limited. ${ }^{31}$ Lastly, there may be limits to the extrapolation of our nationwide results to other countries. Stakeholder perspectives on relevance of outcomes are likely to vary by factors such as organizational care and societal values, and may not be generalizable worldwide. On the other hand, Portugal has not been connoted to any of the "geographical" bronchiolitis definitions, which may be a strength of our study.

In summary, this survey showed paediatricians' and GPs' definitions of bronchiolitis are heterogeneous and often mismatch those of clinical trials. Exploratory component analysis identified domains that underlie different definitions. Our results highlight the need for a robust standardized definition that accommodates relevant subgroups and possibly phenotypes, suiting both 
clinical practice, and research design. Further, we identified outcomes of most relevance to physicians, contributing to the development of a core outcome for future clinical trials.

\section{ACKNOWLEDGMENTS}

We would like to acknowledge Pedro Mendes (Portuguese Society of Paediatrics) for the management of the electronic contact database. We thank the Pulmonology Society of the Portuguese Society of Paediatrics and the Portuguese Association of General Practitioners for their support. Maria Gabriela Andrade was integrated in a research program for MD students (PIATI program) from Associação de Estudantes da Faculdade de Ciências Médicas de Lisboa.

\section{REFERENCES}

1. Smyth RL, Openshaw PJ. Bronchiolitis. Lancet 2006;368:312-322.

2. Bialy L, Foisy M, Smith M, Fernandes RM. The cochrane library and the treatment of bronchiolitis in children: an overview of reviews. Evid Based Child Health 2011;6:258-275.

3. Barben J, Kuehni CE, Trachsel D, Hammer J. Management of acute bronchiolitis: can evidence based guidelines alter clinical practice? Thorax 2008;63:1103-1109.

4. Fernandes RM, Bialy LM, Vandermeer B, Tjosvold L, Plint AC, Patel H, Johnson DW, Klassen TP, Hartling L. Glucocorticoids for acute viral bronchiolitis in infants and young children. Cochrane Database Syst Rev 2013;6:Cd004878.

5. Hartling L, Fernandes RM, Bialy L, Milne A, Johnson D, Plint A, Klassen TP, Vandermeer B. Steroids and bronchodilators for acute bronchiolitis in the first 2 years of life: systematic review and meta-analysis. BMJ 2011;342.

6. Winter ST. Bronchiolitis-What's in a Name? Clin Pediatr (Phila) 1971;10:485-486.

7. McIntosh K. Bronchiolitis and asthma: possible common pathogenetic pathways. J Allergy Clin Immunol 1976;57:595-604.

8. McConnochie KM. Bronchiolitis. What's in the name? Am J Dis Child 1983;137:11-13.

9. Everard ML. Acute bronchiolitis and croup. Pediatr Clin North Am 2009;56:119-133.

10. Court SDM. The definition of acute respiratory illnesses in children. Postgrad Med J 49:771-776.

11. Lakhanpaul M, Armon K, Eccleston P, MacFaul R, Smith S, Vyas H, Werneke U, Williams L, Stephenson T. An evidence based guideline for the management of children presenting with acute breathing difficulty. University of Nottingham. 2002. http://www. nottingham.ac.uk/paediatric-guideline/breathingguideline.pdf (accessed July 2014).

12. Mansbach JM, Camargo CA. Bronchiolitis: lingering questions about its definition and the potential role of vitamin D. Pediatrics 2008;122:177-179.

13. Jartti T, Lehtinen P, Vuorinen T, Ruuskanen O. Bronchiolitis: age and previous wheezing episodes are linked to viral etiology and atopic characteristics. Pediatr Infect Dis J 2009;28:311-317.

14. Frey U, von Mutius E. The challenge of managing wheezing in infants. N Engl J Med 2009;2130-2133.

15. Ducharme FM, Tse SM, Chauhan B. Diagnosis, management, and prognosis of preschool wheeze. Lancet 2014;383:1593-1604.

16. Klassen TP. Determining the benefit of bronchodilators in bronchiolitis. When is there enough benefit to warrant adoption into clinical practice? Arch Pediatr Adolesc Med 1996;150:1120-1121.
17. Tugwell P, Boers M, Brooks P, Simon L, Strand V, Idzerda L. OMERACT: an international initiative to improve outcome measurement in rheumatology. Trials 2007;8:38.

18. Williamson PR, Altman DG, Blazeby JM, Clarke M, Devane D, Gargon E, Tugwell P. Developing core outcome sets for clinical trials: issues to consider. Trials 2012;13:132.

19. Corneli HM, Zorc JJ, Mahajan P, Shaw KN, Holubkov R, Reeves SD, Ruddy RM, Malik B, Nelson KA, Bregstein JS, Brown KM, Denenberg MN, Lillis KA, Cimpello LB, Tsung JW, Borgialli DA, Baskin MN, Teshome G, Goldstein MA, Monroe D, Dean JM, Kuppermann N. Bronchiolitis study group of the Pediatric Emergency Care Applied Research Network (PECARN). A multicenter, randomized, controlled trial of dexamethasone for bronchiolitis. N Engl J Med 2007; 357:331-339.

20. Plint AC, Johnson DW, Patel H, Wiebe N, Correll R, Brant R, Mitton C, Gouin S, Bhatt M, Joubert G, Black KJ, Turner T, Whitehouse S, Klassen TP. Pediatric Emergency Research Canada (PERC). Epinephrine and dexamethasone in children with bronchiolitis. N Engl J Med 2009;360:2079-2089.

21. Jolliffe IT. Principal components used with other multivariate techniques. In: Jolliffe IT, editor. Principal component analysis. New York: Springer New York; 2002. pp 199-231.

22. Subcommittee on Diagnosis and Management of Bronchiolitis. Diagnosis and management of bronchiolitis. Pediatrics 2006;118: 1774-1793.

23. Scottish Intercollegiate Guidelines Network. Bronchiolitis in children: a national clinical guideline. SIGN 2006. Available here: http://www.sign.ac.uk/guidelines/fulltext/91/index.html

24. Mansbach JM, Espinola JA, Macias CG, Ruhlen ME, Sullivan AF, Camargo CA Jr. Variability in the diagnostic labeling of nonbacterial lower respiratory tract infections: a multicenter study of children who presented to the emergency department. Pediatrics 2009; 123:e573-ee81.

25. KorppiM, Koponen P, Nuolivirta K. Upperage limit for bronchiolitis: 12 months or 6 months? Eur Respir J 2012;39: 787-788.

26. Midulla F, Nenna R. Upper age limit for bronchiolitis: 12 months or 6 months? Eur Respir J 2012;39:788-789.

27. Elphick HE, Ritson S, Rigby AS, Everard ML. Phenotype of acute respiratory syncytial virus induced lower respiratory tract illness in infancy and subsequent morbidity. Acta Paediatr 2007;96: 307-309.

28. Sánchez I, Vizcaya C, García D, Campos E. Response to bronchodilator in infants with bronchiolitis can be predicted from wheeze characteristics. Respirology 2005;10:603-608.

29. Spycher BD, Silverman M, Kuehni CE. Phenotypes of childhood asthma: are they real? Clin Exp Allergy 2010;40: $1130-1141$

30. Tugwell P, Boers M, D'Agostino M-A, Beaton D, Boonen A, Bingham CO, 3rd, Choy E, Conaghan PG, Dougados M, Duarte C, Furst DE, Guillemin F, Gossec L, Heiberg T, van der Heijde DM, Hewlett S, Kirwan JR, Kvien TK, Landewé RB, Mease PJ, Østergaard M, Simon L, Singh JA, Strand V, Wells G. Updating the OMERACT Filter: implications of Filter 2. 0 to select outcome instruments through assessment of "Truth": content, face, and construct validity. J Rheumatol 2014;41:1000-1004.

31. Elphick HE, Lancaster GA, Solis A, Majumdar A, Gupta R, Smyth RL. Validity and reliability of acoustic analysis of respiratory sounds in infants. Arch Dis Child 2004;89:1059-1063.

\section{SUPPORTING INFORMATION}

Additional supporting information may be found in the online version of this article at the publisher's web-site. 